\title{
Interrelation between Climate Change and Lightning and its Impacts on Power Sector
}

\author{
Nagarjun.Y \\ Electrical Engineer, Raichur Thermal Power Station Karnataka Power Corporation Limited, India.
}

\begin{abstract}
Thunderstorms and Lightning are climate related, highly localized phenomena in nature known for devastating consequences. These consequences can be seen on power sector which is the lifeblood of modern human activities. As warmer world would be responsible for increased lightning activity, power sector is going to be affected by future climate change and increased lightning activity. This climate change and increased lightning activity introduces new and complex risk factors affecting the power sector's operational performance and resulting in severe damages and blackouts. In this paper how climate change and lightning are correlated and what would be there future impacts on modern power system and how successful the sector will be in tackling the dual challenges of climate change and increased lightning activity are studied. The possible mitigation and corrective actions to be considered by the utility companies and how the development of climate and lightning database to get accurate forecasting would help the utility companies to overcome the impacts of climate change and increased lightning activity are discussed.
\end{abstract}

Keywords: Blackouts, Climate Change, Lightning, Power sector, Renewable energy.

\section{Introduction}

Climate change is a global challenge that will have a major impact on our future business environment. Consumption of fossil fuels is the main contributor to climate change and reducing these emissions is the most important objective of climate change policies. The power sector is a significant emitter of $\mathrm{CO}_{2}$ and therefore key in reducing these emissions. Also recent studies have shown that climate change may lead to fewer but more violent thunderstorms, study says how a changing climate will impact specific elements of weather, such as clouds, rainfall, and lightning. It has been predicted that for every one degree Celsius of warming, there will be approximately a ten percent increase in lightning activity. This could have negative consequences in the form of flash floods, wild fires, or damage to power lines and other infrastructure [1]. While rainfall and lighting are positively correlated on time scales of individual storms, on climate spatial and temporal scales, rainfall is negatively correlated to lightning, with drier regions having more lightning. During the 1998 severe drought conditions were experienced in Indonesian and South-East Asia, but with a 57\% increase in lightning activity. It was shown that there were less thunderstorms overall, but they were more intense than normal.

Climate change and increased lightning activity introduces new and complex risk factors affecting the power sector's operational performance. Therefore more likely to be successful the power sector must manage to control risk and take advantage of the opportunities in times when the business environment is changing. In this paper the changing risk picture for the power sector will be examined. Through various studies, it is identified the risks and opportunities that the power sector views as most important to the sector and their companies, as well as the corresponding strategic directions utility companies are considering as a consequence of climate change and lightning. Potential risk mitigating strategies and strategies that utility companies could implement to reduce risk and capture the full potential of the opportunities are discussed.

\section{Climate Change And Lightning}

There have been numerous papers in the past few years dealing with the connection between lightning, climate and climate change [1]. Due to the interest in global warming, there have been numerous studies looking at the relationship and sensitivity of lightning activity to changes in surface temperature. Since long term global lightning observations do not exist, relationships are normally investigated on shorter time scales. Many time scales have been explored; on all these timescales we observe a positive relationship between temperature and lightning. Recent studies continue to show the high positive correlation between surface temperatures and lightning activity [2]

There is solid evidence that global temperatures are increasing, and the cause is very likely due to the increasing anthropogenic greenhouse gases in the atmosphere (IPCC, 2007) [3]. However, since we do not know how lightning and thunderstorms will react to a warmer world, we need to use climate change proxies from the present and past, or we need to run computer simulations of how global warming may impact thunderstorms in a future climate. Hence, we need to be cautious when extrapolating present day variability to future global warming. 
According to the 2007 United Nations report on climate change, an increase in lightning activity will have particular impact in areas that become warmer and drier as global warming progresses, including the Mediterranean and the Southern United States [4, 5]. There is increasing evidence that the earth's climate is changing and global temperatures are increasing. Well, changes in temperature, precipitation and sea level can affect us in many different ways depending on where we live. The tropics will be affected differently to midlatitude regions. Coastal regions will see different impacts compared with inland regions. Dry regions may become drier, while wet regions may be wetter.

Two possible implications of a warmer climate are the possibility of more frequent and more intense thunderstorms, possibly leading to more flash floods and severe weather. In some regions climate models predict an increased frequency of drought around the globe, with natural forest fires becoming more common, and more damaging. This article is interested in such implications of future climate change on power sector. The Fig. 1 below shows the changes in lightning activity in an atmosphere with twice today's concentration of $\mathrm{CO}_{2}$ (equivalent to a $4^{\circ} \mathrm{C}$ warming in the NASA/GISS model ). Note that although globally the model predicts an increase of $30 \%$ in the global lightning activity, most of this change occurs of the continental regions. Note that there are some regions (blue) where the model predicts decreases in thunderstorm activity. Although confidence in the regional changes is very low with these coarse-resolution climate models, the global trends are fairly robust from model to model. It is also shown that lightning and thunderstorms also prefer drier climates relative to moist climates. While Africa has much more lightning activity than the Amazon regions, the rainfall in the Amazon is greater than over Africa.

As the climate warms and dry in some regions, it may be these regions that experience more intense thunderstorm activity, while areas that get warmer and wetter see less thunderstorm and lightning activity. But there is need to wait and see the future changes in this matter. In addition to the lightning activity increasing in a warmer climate, the small changes in surface temperature result in large changes in the lightning activity. Hence the global lightning activity may be used to amplify any climate change signal.

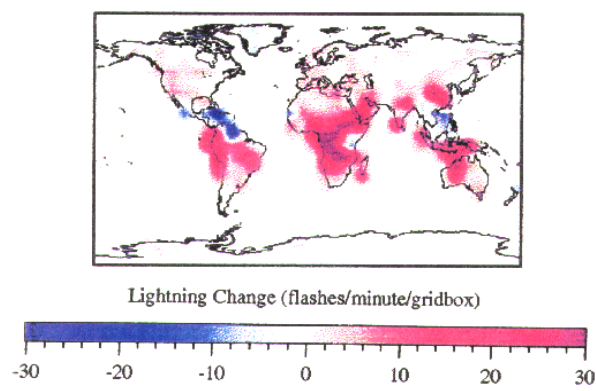

Fig.1. Changes in lightning activity in an atmosphere with twice today's concentration of $\mathrm{CO}_{2}($ Source: www.tau.ac.il)

Also it is well known that lightning is a major source of nitrogen oxides $\left(\mathrm{NO}_{\mathrm{x}}\right)$ in the atmosphere [6, 7], which are a precursor for ozone $\left(\mathrm{O}_{3}\right)$ production in the troposphere. Since $\mathrm{O}_{3}$ is also a greenhouse gas, changes in lightning activity may result in an additional warming (positive feedback) on the climate system. Lightning discharges in thunderstorms are an indication of the intensity of atmospheric convection. If we change the climate we will change the regions of convection, their intensity, and hence will likely change the lightning patterns around the globe.

\section{Impacts Of Climate Change On Power Sector}

Climate change is introducing new risks and opportunities to the power sector. Some of the usual suspects turn up again, but the causes of risks and opportunities are somewhat different because of the unique challenges presented by climate change.

\subsection{Increased demand for electricity}

The main opportunity for the utility companies is the expected increase in the demand for electricity. Increasing demand for electricity is a fundamental global trend due to a growing world population and millions of people in the developing world increasing their standard of living. Access to reliable and affordable energy is a fundamental factor for economic growth and will be the driving force behind increased demand for electricity.

The demand for electricity is expected to increase most in the developing economies. The objective of climate change policies is to shift energy demand towards energy carriers and sources such that the global energy mix is far less carbon intensive than today. These policies will stimulate more electricity generation 
based on renewables and nuclear, and fossil fuelled power plants to become less carbon intensive - for example switching from coal to natural gas or investing in carbon capture and storage technologies. There is also a trend with energy end-users switching from fossil fuels to electricity in order to reduce own $\mathrm{CO}_{2}$ emissions and take advantage of innovations in energy end use. Examples are industries replacing production facilities based on heat/electricity from oil with processes based on electricity from the grid or the impact of a potential technical and commercial breakthrough of electric vehicles.

\subsection{Increased power generation capacity}

The main risk for the power sector is that it fails to increase the supply of electricity to meet the expected increase in demand. This would lead to higher electricity prices and increase the risk of power failures.

The main challenge for the power sector is to increase the supply of electricity. This could be accomplished by investing in $\mathrm{CO}_{2}$-free power generation capacity i.e. renewables and nuclear, or by investing in $\mathrm{CO}_{2}$-reduced generation capacity i.e. switching from coal to gas or application of Carbon Capture and Storage (CCS). Today, there are challenges related to all of these alternatives - technological, financial and public acceptance. However, in any case the sector will have to gradually replace existing fossil based power generation capacity and build additional power generation capacity with cleaner energy. The sector has increased motivation to develop technologies and incentive mechanisms that reduce the demand for electricity. The rationale behind this behaviour will be to avoid additional costly investments in generation capacity or in transmission and distribution.

\subsection{Transmission and distribution}

In most countries a changing energy mix with more decentralised electricity generation due to an increasing share of renewable energy is challenged by the existing transmission and distribution grids. The grids are designed to distribute electricity from large base load power plants to end-users. Today, however, transmission and distribution grids are aging and have been suffering from low investments for the last two decades, which have resulted in overloaded networks and increased risk of power failures. If the power sector is going to increase the share of renewables in the energy mix the industry needs to develop transmission and distribution networks adapted to deliver clean energy. There is also potential for smartening the grids (i.e. making them more efficient) by implementing new technologies. Policy makers will play an important role in regulating the transmission and distribution grids that will support the increasing generating capacity from renewables.

\subsection{Operational effects of climate change}

The power sector faces the risks and opportunities caused by a changing climate. More extreme weather events, higher temperatures and more or less rainfall will influence the operations of the power sector.

Key questions are: How will higher temperatures of cooling water influence nuclear or fossil fuelled power plants? What will be the impact of extreme weather events on the operation of power plants and transmission grids? Will production from hydro power plants increase due to more rainfall? Today, such direct climate change effects are already affecting power generation and transmission to some extent and the impact of these effects are expected to increase in the future.

\section{Impact Of Increased Lightning Activity On Power Sector}

The mission of modern and future power systems is to supply electric energy satisfying conflicting requirements: but due to the problems raised by climate change and increased lightning activity, this would be a difficult task for the utility companies to meet. And due to this the number of power outages due to lightning strikes will increase.

Though lightning may directly cause physical damages to power system components, sometimes it results in initiating events which leads to severe blackouts or outages. The initiating event or events can include a line sagging into vegetation, or a short on a transmission line caused by natural causes such as high wind or lightning $[8,9]$. Other initiating events can include human actions (or inaction), the particular network topology at the time, and or imbalances between load and generation. These events cause cascading outages [10] which typically occur in rapid succession such that human intervention is unable to stop the process. The outages include sequential tripping of transmission lines and generators.

When thunder and lightning do occur, however, lightning strikes can cause major damage such as blackouts, as well as serious injuries to people $[9,11]$, damage to home appliances powered by electricity [12].

However, because computer systems are particularly vulnerable to lightning surges, lightning damage to data networks is actually increasing. For example, if lightning causes a mere $20 \mathrm{~ms}, 30 \%$ voltage fluctuation, the shock waves may cause a system to malfunction or lose data. If this happens to a company's or public institution's core computer, it may negatively impact not just a single computer system, but society as a whole 
$[13,14]$. With the spread of IT environments, the risk of lightning damage to networks may increase every year. Furthermore, there are also recent reports of damage to wind and solar power generation, which is a desirable renewable energy source for the building of a sustainable society. Adoption of renewable energy sources is advancing in most countries in particular as a measure against problems such as global warming and petroleum depletion. Because wind and solar power generation rely on nature, there are many issues like this which needs to be taken care off. Lightning damage countermeasures are therefore essential for the adoption of wind power generation to power sector.

\section{Mitigation And Corrective Actions}

The surveys show that utility companies expect an increase in the risks relating to their operational performance as a consequence of climate change and increased lightning activity, which means that additional measures will be required to manage these risks. Correspondingly, a successful utility applies business strategies that take advantage of the opportunities that arise from climate change. The following mitigation and corrective actions are to be considered by the utility companies:

- Diversifying the energy portfolio for reducing $\mathrm{CO}_{2}$ emissions by transitioning to $\mathrm{CO}_{2}$-free energy production using renewable energy, or by transitioning to $\mathrm{CO}_{2}$-reduced fossil energy production by switching from coal to gas, or by use of CCS.

- Expanding the business model to reduce vulnerability, e.g. through mergers and acquisitions, geographical expansion, increased control over the entire energy value chain or new price models.

- Adaptation to climate change to reduce operational exposure through location of plants and access to cooling water.

- Political lobbying to influence the regulatory framework and brand management so the power sector will be perceived as being part of the solution to climate change.

Lightning countermeasures that should be considered are: To develop a Database and accurate forecasting and also accurate global lightning detection is necessary to overcome the effect of increased lightning activity [15]. The ability to forecast lightning strike locations in advance would simplify the prevention of lightning damage. This requires an understanding of the dynamics inside thunderclouds to clarify the distribution of charges. Furthermore, it is necessary to measure the progress of discharges using systems that combine radar and interferometers and to pursue research on lightning discharges. Regarding observation, observing lightning from space will enable scientific elucidation of the correlation between lightning activity and global warming. This will require cross-sectoral research spanning electrical engineering, meteorological engineering, and space engineering. Because the occurrence of lightning varies by season and location, countermeasures specific to local characteristics are necessary. For example, the difference in current between weak lightning and strong lightning is a factor of 100 . Countermeasures that address intermediate lightning will not work against strong lightning.

Power sector must be provided with an extremely valuable dataset of climate and lightning to improve analysis, nowcasts, and forecasts around the world. Continuous thunderstorm identification and tracking around the world will not only improve global thunderstorm nowcasts, but also nowcasts of precipitation, severe weather, turbulence, high seas and tropical cyclone intensity. Lightning dataset must provide lightning-sensitive facilities, with an effective way to produce Cloud to Ground (CG) lightning warnings which can be used to generate CG lightning warnings for Wind Energy and outdoor recreation. Wind Energy workers typically only need appropriate warnings and can be productive on other tasks while the CG lightning hazard exists. The impact of these applications will result in savings of man, money, and machines.

Also global lightning detection is important for understanding climate change and its impact on society. There are many questions that remain unanswered concerning global climate change and global lightning production. These questions can be answered with a long record of lightning activity on a global scale.

\section{Conclusion}

It is clear that the spatial and temporal distributions of lightning activity on Earth are governed by the climate itself $[16,17]$. On short time scales (hourly, daily, monthly and annual) there appears to be a robust positive correlation between tropical lightning activity and surface temperature, upper tropospheric water vapour, cloud cover, and anvil ice content [18]. Whether these relationships hold on longer time scales is still uncertain, although climate models do support the positive correlation between lightning and global temperatures. Climate models provide some insight into this paradox that shows more lightning with less rainfall, since they too predict increasing lightning activity as the climate warms and dries. Both regionally and globally climate models predict increases in lightning activity in a warmer climate, even though the atmosphere becomes more stable and the surface tends to dry as the climate warms. 
The utility companies around the world expect an increase in the risk levels for their operational performance as a consequence of climate change or lightning, and that additional measures will be required to manage these risks. These measures incorporate both mitigation actions to reduce the likelihood of an exposure, and corrective actions to reduce the consequence of the exposure should it occur. Also the power sector will have to play a vital role in the necessary transformation of our fossil fuelled economies towards a future low carbon economy. How successful the sector will be in tackling the dual challenges of climate change and increased lightning activity will, among other things, depend on whether the sector will be able to adapt to this new risk reality.

\section{References}

[1] Colin Price "Thunderstorms, Lightning and Climate Change" 29th International Conference on Lightning Protection, -Uppsala, Sweden, (23rd-26 ${ }^{\text {th }}$, June 2008).

[2] Pinto, O., Jr., And I. R. C. A. Pinto (2008), "On the Sensitivity of Cloud-to-Ground Lightning activity to surface air temperature changes at different timescales in Sa O Paulo, Brazil”, J. Geophys. Res., 113, D20123, DOI: 10.1029/2008JD009841, (2008).

[3] United Nations Intergovernmental Panel on Climate Change (IPCC 2007). "Climate Change 2007" Synthesis Report-Fourth Assessment Report, (2007).

[4] Yoav Yair, Barry Lynn, Colin Price, Vassiliki Kotroni, Konstantinos Lagouvardos, Efrat Morin, Alberto Mugnai, Maria Del Carmen Llasat. "Predicting the potential for lightning activity in Mediterranean Storms based on the Weather Research and Forecasting (WRF) Model dynamic and Microphysical Fields". Journal of Geophysical Research, DOI: 10.1029/2008JD010868, pp-115(D4), (2010).

[5] Moriah Kohn, Eli Galanti, Colin Price, Kostas Lagouvardos, Vassiliki Kotroni. : "Nowcasting thunderstorms in the Mediterranean region using lightning data". Atmospheric Research, DOI:10.1016/j.atmosres.2010.08.010, pp-100(4) 489, (2011).

[6] Zhang Yijun, Ma Ming, Lu Weitao, Et Al:: "Review on Climate Characteristics of Lightning activity". Acta. Meteor. Sinica, 24(2), pp137-149, (2010).

[7] Christian Bouquegneau, Vladimir Rakov "How Dangerous is lightning?” Dover Publications, ISBN-13:978-0-486-47704-6, pp-116, (2010)

[8] Pan L X, Qie X S, Liu D X, "The Lightning activities in Super Typhoons over the Northwest Pacific". Sci. China Earth Sci., DOI: 10.1007/S11430-010-3034-Z, 53: pp-1241-1248, (2010).

[9] Colin Price1, Mustafa Asfur And Yoav Yair. "Maximum Hurricane Intensity preceded by Increase in Lightning Frequency", Nature Geoscience, Published Online: 6 April 2009 | DOI: 10.1038/ngeo477, (2009).

[10] EPRI Report "Mitigating Cascading Outages on Power Systems: Recent Research Approaches and Emerging Methods", EPRI, Palo Alto, Ca: 2005. 1010701, (2005)

[11] Price, C., Y. Yair, And M. Asfur, "East African Lightning as a Precursor of Atlantic Hurricane Activity", Geophys. Res. Lett., 34 , L09805, DOI: 10.1029/2006g1028884, (2007).

[12] EPRI Technical Report "Switching Surge and Lightning Impact on Increasing Power Flow". EPRI, Palo Alto, Ca: 2006. 1012404, (2006)

[13] Kuniko Urashima, "Considering of Lightning Damage Protection and Risk Reduction for a Safe and Secure Society", Science \& Technology Trends, Quarterly Review No. 25 / pp 21-35, (October 2007).

[14] Baharuddin, M.Z.; Abidin, I.Z.; Hashim, A.H.; Hussein, H.; Chin, Y.E.; Mohamad, A.M., "Application of Lightning Performance Analysis for a Tropical Climate Country," Power And Energy Conference, 2006. PECON '06. IEEE International, pp.591-596, DOI: 10.1109/pecon.2006.346720, (28-29 Nov. 2006).

[15] Ben Ma; Haiqing Li; Rong Yuan; Rui Sun; Hu Wan, "Grid Analysis of Lightning Parameters Based on GIS," Quality, Reliability, Risk, Maintenance, and Safety Engineering (ICQR2MSE), 2011 IEEE International Conference, Vol., No., pp.983-985, 17-19 June 2011 DOI: 10.1109/Icqr2mse.2011.5976768,(June 2011).

[16] Williams, E.R.: "Lightning and Climate: A Review", Atmos.Res. 76, pp272-287, (2005).

[17] Reeve, N., and R. Toumi,: "Lightning activity as an Indicator of Climate Change", Quart. J. Roy. Met. Soc., 125, pp893-903, 1999).

[18] Price, C., And D. Rind, "Possible Implications of Global Climate Change on Global Lightning Distributions and Frequencies, J. Geophys. Res., 99, pp10823-10831, (1994). 